\title{
Troglostrongylus brevior and Troglostrongylus subcrenatus (Strongylida: Crenosomatidae) as agents of broncho-pulmonary infestation in domestic cats
}

Emanuele Brianti ${ }^{*}$, Gabriella Gaglio ${ }^{1}$, Salvatore Giannetto ${ }^{1}$, Giada Annoscia$^{2}$, Maria Stefania Latrofa ${ }^{2}$, Filipe Dantas-Torres ${ }^{2,3}$, Donato Traversa ${ }^{4}$ and Domenico Otranto ${ }^{2}$

\begin{abstract}
Background: Aelurostrongylus abstrusus is currently regarded as the main metastrongyloid infesting domestic cats, whereas the reports of Troglostrongylus spp. in domestic and wild felids largely remain anecdotic. This paper reports on pulmonary infestation caused by Troglostrongylus brevior and Troglostrongylus subcrenatus in two kittens and describes, for the first time, associated clinical presentations and pathological features. Morphometrical, molecular and phylogenetic analyses have also been conducted to differentiate here the examined Troglostrongylus species from A. abstrusus, towards a clearer delineation of metastrongyloids affecting cats.

Methods: Two kittens were referred for respiratory distress and hospitalized with a diagnosis of severe aelurostrongylosis, based on the presence of metastrongyloid larvae in the faeces. Despite prompt treatment, kittens died within 48 hours. Both kittens were submitted to necropsy to determine the cause of death.

Results: At necropsy, nematode specimens were found in the trachea, bronchi and bronchioles and were associated with respiratory signs (i.e., dyspnoea, polypnea, severe coughing and nasal discharge). Morphology and measurements of adult parasites found allowed the unequivocal identification of T. brevior and T. subcrenatus, even if first stage larvae were rather similar to those of A. abstrusus. Briefly, T. brevior and T. subcrenatus larvae were shorter in length and lacking the typical knob-like terminal end of A. abstrusus. Molecular and phylogenetic analyses corroborated morphological identification and provided data on mitochondrial and ribosomal DNA genes of T. brevior.

Conclusions: Data presented here indicate that T. brevior and T. subcrenatus may cause major respiratory distress in domestic cats. Consequently, these two species should be included, along with A. abstrusus, in the differential diagnosis of cat bronchopulmonary affections and treatment protocols need to be evaluated. Through research on the biology, epidemiology and control of Troglostrongylus spp. infestations in domestic cats are advisable to implement current knowledge on these neglected metastrongyloids.
\end{abstract}

Keywords: Aelurostrongylus abstrusus, Cat, Diagnosis, Italy, Metastrongyloidea, Molecular biology, Troglostrongylus brevior, Troglostrongylus subcrenatus

\footnotetext{
* Correspondence: ebrianti@unime.it

${ }^{1}$ Dipartimento di Sanità Pubblica Veterinaria, Facoltà di Medicina Veterinaria,

Università degli Studi di Messina, Messina, Italy

Full list of author information is available at the end of the article
} 


\section{Background}

Nematode infestations of the cardio-pulmonary system of dogs and cats have recently gained thescientific interest of researchers and practitioners, due to the clinical severity of the conditions they cause and to their spread throughout many Europeancountries [1-3]. Among them, Aelurostrongylus abstrusus (Strongylida: Angiostrongylidae) is commonly regarded as the only metastrongyloid of domestic cats $[4,5]$. Broncho-pulmonary infestations by A. abstrusus are widespread throughout most European countries with prevalence rates ranging from $1 \%$ to $24.4 \%$, according to sampled populations and detection procedures (e.g., copromicroscopy or molecular detection) [2,6-12]. Actually, other metastrongyloids have been reported as causative agents of respiratory infestation in domestic cats. For instance, Oslerus rostratus (Strongylida: Filaroididae) has been recorded to infest the pulmonary system of cats with prevalence rates up to $24 \%$ in Spain [13,14]. Meanwhile, Troglostrongylus subcrenatus (Strongylida: Crenosomatidae) was retrieved once at the necropsy of a domestic cat from Blantyre (Nyasaland, Malawi) [15] and, larvae of a yet unclassified Troglostrongylus sp. have recently been identified in faeces of domestic cats from Ibiza (Spain), which exhibited respiratory disease [16].

The genus Troglostrongylus encompasses four nematode species (i.e., T. brevior, T. subcrenatus, T. troglostrongylus and $T$. wilsoni), which are commonly found in the trachea and bronchi of wild felids [17-21]. Albeit scantly studied, Troglostrongylus spp. display an indirect life cycle similar to that of $A$. abstrusus, with terrestrial molluscs serving as intermediate hosts and small mammals (e.g., mice) as paratenic ones [4,22,23]. Larvae of $T$. brevior may develop in several species of molluscs (i.e., Helicella barbesiana, Helicella vestalis, Limax flavus, Monacha syriaca, Retinella nitellina and Theba pisana), becoming infective from 8 to 40 days depending on the environmental temperature (i.e., between $22^{\circ}-27^{\circ} \mathrm{C}$ and between $4^{\circ}-8^{\circ} \mathrm{C}$, respectively) [17]. Nonetheless, the scant scientific information available on the distribution and pathogenicity of Troglostrongylus sp. in domestic cats [16] might indicate that this infestation occurs sporadically or that it is misdiagnosed with the commonest A. abstrusus.

This paper reports on pulmonary infestation by $T$. brevior and T. subcrenatus in two kittens and describes, for the first time, associated clinical presentations and pathological features. Additionally, morphometric, molecular and phylogenetic analyses have also been conducted to differentiate the Troglostrongylus species here examined from $A$. abstrusus towards a clearer delineation of metastrongyloids affecting cats.

\section{Methods}

\section{Case description}

A 3-month-old female privately owned kitten (case 1), and a 3-month-old female stray kitten (case 2) were referred to the Faculty of Veterinary Medicine of Messina (Sicily region, Italy) on April 2010 and June 2011. Both animals exhibited respiratory signs such as dyspnoea, polypnea, severe coughing and nasal discharge (see Additional file 1 and Additional file 2). In addition, case 1 had developed inappetence and lethargy in the $48 \mathrm{~h}$ prior to referral while case 2 was dehydrated and in poor general condition at the moment of the clinical examination. Thoracic radiographs, performed only for case 2, showed diffuse increase of radiograph density and marked bronchial pattern in diaphragmatic lobes. Leucocytosis (i.e., $26.3 \times 10^{3} / \mu \mathrm{l}$ in case 1 , and $20.9 \times 10^{3} / \mu \mathrm{l}$ in case 2 ) was diagnosed while biochemistry was within normal limits in both cases. Toxocara cati eggs were detected at the copromicroscopy using the flotation method in case 1 and of nematode larvae, resembling those of A. abstrusus, were retrieved by the Baermann technique in both cases. Kittens were both hospitalized with a diagnosis of severe aelurostrongylosis and antiparasitic drugs (imidacloprid $10 \mathrm{mg} / \mathrm{kg} /$ moxidectin $1 \mathrm{mg} / \mathrm{kg}$ spot-on in case 1 , and fenbendazole $50 \mathrm{mg} / \mathrm{kg}$ PO once every $24 \mathrm{~h}$ in case 2 ) were administered. Both kittens also underwent systemic therapy with intravenous fluids, antibiotics (amoxicillin $20 \mathrm{mg} / \mathrm{kg}$ IV twice every $24 \mathrm{~h}$ and enrofloxacin $5 \mathrm{mg} / \mathrm{kg}$ IV once every $24 \mathrm{~h}$ ) and placed in an oxygen chamber but they did not show any improvement with exitus within 24-48 h after hospitalization. Animals were not enrolled in any experimental trial. Kittens were hospitalized and keep according to Animal Welfare and Good Clinical Practice (VICH GL9-GCP, 2 "Good Clinical Practice", CVMP, June 2000) guidelines. In both cases necropsy was requested and authorized by the owners.

\section{Pathological findings and parasite identification}

Carcasses of both kittens were subjected to necropsy. Parasitic specimens collected from lungs were washed in saline solution and stored in $70 \%$ ethanol (case 1) and in formalin (case 2). Worms were individually mounted on slides by the glycerol-ethanol method and microscopically observed. Microscopic images and measures were taken by using a digital image processing system (AxioVision rel. 4.8, Carl Zeiss, Germany). Parasites were sexed and identified at the species level by morphometrical and morphological keys $[15,17,23]$. Slidemounted specimens of both sexes were stored in the parasite collection of the Faculty of Veterinary Medicine of Messina. In addition, gross anatomical findings, anatomical localization of parasites, and their morphometric features were also compared with those from A. abstrusus from a road-killed stray cat (E.B. unpublished observations). 
Table 1 GenBank $^{\mathrm{TM}}$ accession numbers (AN) of the Metastrongyloidea used in the phylogenetic analyses for 18S rRNA and the internal transcribed spacer 2 (ITS2) genes

\begin{tabular}{|c|c|c|c|c|}
\hline DNA region & Species & Host & Country & AN \\
\hline \multirow[t]{32}{*}{$18 \mathrm{~S}$} & Aelurostrongylus abstrusus & Felis catus & - & AJ920366 \\
\hline & Angiostrongylus costaricensis & Sigmodon hispidus & - & EF514913 \\
\hline & Angiostrongylus costaricensis & - & - & DQ116748 \\
\hline & Angiostrongylus dujardini & Myodes glareolus & - & EF514915 \\
\hline & Angiostrongylus malaysiensis & Rattus tiomanicus & - & EF514914 \\
\hline & Angiostrongylus vasorum & Vulpes vulpes & - & EF514916 \\
\hline & Angiostrongylus vasorum & Vulpes vulpes & - & AJ920365 \\
\hline & Crenosoma mephitidis & Mephitis mephitis & USA & AY295805 \\
\hline & Crenosoma sp. & Ailurus fulgens & - & GU475120 \\
\hline & Crenosoma striatum & Erinaceus europaeus & UK & GU214747 \\
\hline & Crenosoma vulpis & Vulpes vulpes & - & AJ920367 \\
\hline & Didelphostrongylus hayesi & Didelphis virginiana & USA & AY295806 \\
\hline & Filaroides martis & Neovison vison (=Mustela vison) & Canada & AY295807 \\
\hline & Halocercus invaginatus & Phocoena phocoena & USA & AY295808 \\
\hline & Metastrongyloidea sp. & Ailurus fulgens & - & GU475121 \\
\hline & Metastrongylus elongatus & Sus scrofa & - & AJ920363 \\
\hline & Metastrongylus salmi & Sus scrofa & USA & AY295809 \\
\hline & Muellerius capillaris & Ovis aries & USA & AY295810 \\
\hline & Nippostrongylus brasiliensis & Rattus sp. & - & AJ920356 \\
\hline & Oslerus rostratus & Lynx rufus & USA & GU946678 \\
\hline & Oslerus osleri & Canis latrans & USA & AY295812 \\
\hline & Otostrongylus circumlitus & Mirounga angustirostris & USA & AY295813 \\
\hline & Otostrongylus sp. & - & - & OSU81589 \\
\hline & Parafilaroides decorus & Zalophus californianus & USA & AY295814 \\
\hline & Parafilaroides sp. & - & - & U81590 \\
\hline & Protostrongylus rufescens & Ovis aries & - & AJ920364 \\
\hline & Pseudalius inflexus & Phocoena phocoena & USA & AY295816 \\
\hline & Skrjabingylus chitwoodorum & Mephitis mephitis & USA & AY295819 \\
\hline & Stenurus minor & Phocoena phocoena & USA & AY295817 \\
\hline & Torynurus convolutus & Phocoena phocoena & USA & AY295818 \\
\hline & Troglostrongylus sp. & Felis catus & Spain & GU946677 \\
\hline & Troglostrongylus wilsoni & Lynx rufus & USA & AY295820 \\
\hline \multirow[t]{11}{*}{ ITS2 } & Aelurostrongylus abstrusus & Felis silvestris catus & Italy & DQ372965 \\
\hline & Aelurostrongylus abstrusus & Felis silvestris catus & Italy & EU034168 \\
\hline & Angiostrongylus dujardini & Apodemus sylvaticus & France & GQ181113 \\
\hline & Angiostrongylus vasorum & Canis familiaris & Germany & GU045375 \\
\hline & Elaphostrongylus alces & Alces alces & Sweden & AF504028 \\
\hline & Elaphostrongylus alces & Alces alces & Sweden & AF504034 \\
\hline & Elaphostrongylus cervi & Cervus elaphus & New Zealand & AF504032 \\
\hline & Elaphostrongylus cervi & Cervus elaphus & New Zealand & AF504026 \\
\hline & Elaphostrongylus rangiferi & Rangifer tarandus & Canada & AY648408 \\
\hline & Elaphostrongylus rangiferi & Rangifer tarandus & Canada & AF504027 \\
\hline & Elaphostrongylus rangiferi & Rangifer tarandus & Canada & AF504033 \\
\hline
\end{tabular}


Table $1 \mathrm{GenBank}^{\mathrm{TM}}$ accession numbers (AN) of the Metastrongyloidea used in the phylogenetic analyses for 18S rRNA and the internal transcribed spacer 2 (ITS2) genes (Continued)

$\begin{array}{llll}\text { Halocercus invaginatus } & - & - & \text { FJ787301 } \\ \text { Metastrongylus asymmetricus } & \text { Sus scrofa } & - & \text { Y08006 } \\ \text { Metastrongylus elongatus } & \text { Sus scrofa } & \text { Estonia } & \text { AJ305377 } \\ \text { Metastrongylus elongatus } & \text { Sus scrofa } & \text { Estonia } & \text { AJ305376 } \\ \text { Metastrongylus elongatus } & \text { Sus scrofa } & \text { Estonia } & \text { AJ305381 } \\ \text { Metastrongylus pudendotectus } & \text { Sus scrofa } & - & \text { Y08008 } \\ \text { Muellerius capillaris } & \text { Ovis aries } & \text { Canada } & \text { AY679527 } \\ \text { Muellerius capillaris } & \text { Ovis aries } & \text { Canada } & \text { AY679528 } \\ \text { Nematodirus battus } & - & - & \text { JF345079 } \\ \text { Otostrongylus circumlitus } & \text { Mirounga angustirostris } & \text { AF130455 } \\ \text { Parelaphostrongylus odocoilei } & \text { Ovis aries } & \text { Canada } & \text { AY648402 } \\ \text { Parelaphostrongylus odocoilei } & \text { Odocoileus hemionus hemionus } & \text { Canada } & \text { AF504031 } \\ \text { Parelaphostrongylus tenuis } & \text { Odocoileus virginianus } & \text { Canada } & \text { AF504035 } \\ \text { Parelaphostrongylus tenuis } & \text { Odocoileus virginianus } & \text { Canada } & \text { AF504029 } \\ \text { Pseudalius inflexus } & - & - & \text { FJ767935 } \\ \text { Stenurus minor } & - & - & \text { FJ787302 } \\ \text { Torynurus convolutus } & - & \text { AY464532 }\end{array}$

Nippostrongylus brasiliensis and Nematodirus battus were used as outgroups.

\section{Molecular procedures and analyses}

The molecular identification was performed by extracting genomic DNA from two parasite specimens of case 1 using a commercial kit (DNeasy Blood \& Tissue Kit, Qiagen, GmbH, Hilden, Germany) in accordance with the manufacturer's instructions. Unfortunately, all attempts to extract genomic DNA from nematodes retrieved from case 2 failed, probably because the specimens were kept in formalin.

A mitochondrial partial cytochrome $c$ oxidase subunit 1 gene (pcox1, $400 \mathrm{bp}), 18 \mathrm{~S}(\sim 1700 \mathrm{bp})$ and internal transcribed spacer 2 (ITS2, $630 \mathrm{bp}$ ) of ribosomal RNA gene were amplified. In particular, pcox 1 was amplified by using the degenerated set of primers TcoxF (5'-TGGARYTRTC TAARCCNGG-3') and TcoxR (5'-GGAGGATAHACHG TYCAHC-3'), which was designed, using the criteria of Sharrocks [24], on the basis of the consensus sequences obtained by the multiple alignment of sequences of Metastrongyloidea available in GenBank ${ }^{\mathrm{TM}}$ (Table 1). The $18 \mathrm{~S}$, ITS2 and flanking sequences of the $5.8 \mathrm{~S}$ and $28 \mathrm{~S}$ rRNA genes were amplified by two sets of primers (NC18SF1: 5'-AAAGATTAAGCCATGCA-3' and NC5BR: 5'- GCAGGTT CACCTACAGAT-3'; D: 5'-GAGTCGATG AAGAACGCAG-3' and B: 5'-GAATTCTGGTTAGTTTC TTTTCCT-3', respectively) $[25,26]$. Each reaction for pcox 1 and $18 \mathrm{~S}$ consisted of $4 \mu \mathrm{l}$ genomic DNA and $46 \mu \mathrm{l}$ of PCR mix containing $2.5 \mathrm{mM} \mathrm{MgCl} 2,10 \mathrm{mM}$ Tris- $\mathrm{HCl}$, $\mathrm{pH} 8.3$ and $50 \mathrm{mM} \mathrm{KCl}, 250 \mu \mathrm{M}$ of each dNTP, $50 \mathrm{pmol}$ of each primer and 1.25 $\mathrm{U}$ of Ampli Taq Gold (Applied
Biosystems). Approximately $100 \mathrm{ng}$ of genomic DNA were added to each PCR and samples without DNA were included with each batch of sample tested. The pcox 1 were amplified using the following conditions: $95^{\circ} \mathrm{C}$ for $10 \mathrm{~min}$ (first polymerase activation and denaturation); followed by 35 cycles of $95^{\circ} \mathrm{C}$ for 1 min (denaturation); $48^{\circ} \mathrm{C}$ for $1 \mathrm{~min}$ (annealing), $72^{\circ} \mathrm{C}$ for $1 \mathrm{~min}$ (extension); and a final extension at $72^{\circ} \mathrm{C}$ for $7 \mathrm{~min}$. The PCR of $18 \mathrm{~S}$ and ITS2 were carried out by $30-40$ cycles of $94^{\circ} \mathrm{C}$ for $30 \mathrm{sec}$ (denaturation), $72^{\circ} \mathrm{C}$ for $1 \mathrm{~min}$ and $45 \mathrm{sec}$ (extension), and annealing temperatures of $57-58^{\circ} \mathrm{C}$ for $30-45 \mathrm{sec}$, respectively. Polymerase activation and denaturation and final extension were similar to those above. All amplicons were resolved in ethidium bromide-stained (2\%) agarose (Gellyphor, Euroclone, Italy) gels and sized by comparison with markers in the Gene Ruler ${ }^{\mathrm{TM}} 1 \mathrm{~kb}$ DNA Ladder (MBI Fermentas, Vilnius, Lithuania). Gels were photographed by a digital documentation system (Gel Doc 2000, BioRad, UK). Amplicons were purified using Ultrafree-DA columns (Amicon, Millipore; Bedford, USA) and then sequenced directly using the Taq DyeDeoxyTerminator Cycle Sequencing Kit (v.2, Applied Biosystems) in an automated sequencer (ABI-PRISM 377).

Sequences were determined from both strands (using the same primers individually as for the PCR) and the electropherograms verified by eye. In order to ensure open reading frames, the nucleotide sequence 
of pcox 1 was conceptually translated into amino acid sequence using the invertebrate mitochondrial code MEGA5 software [27]. Sequences for all genes were compared with those available in the GenBank ${ }^{\text {ma }}$ database by Basic Local Alignment Search Tool (BLAST) [28]. In order to investigate the relationships among metastrongyloids affecting wild and domestic carnivores, sequences of $18 \mathrm{~S}$ and ITS2 were analysed with those available in GenBank ${ }^{\mathrm{TM}}$ (Table 1) and the evolutionary history was inferred using the neighbourjoining method [29]. The bootstrap consensus trees inferred from over 7,000 replicates were taken to represent the evolutionary history of the taxa analysed [30]. Branches corresponding to partitions reproduced in less than $50 \%$ bootstrap were collapsed and the percentage of replicate trees in which the associated taxa clustered together in the bootstrap test was shown next to the branches [30]. Phylogenetic analyses were conducted in MEGA5 software [27]. Sequences of Nippostrongylus brasiliensis (Strongylida: Heligmonellidae) and Nematodirus battus (Strongylida: Molineidae) were used as outgroups. The nucleotide sequences analyzed in this paper are available in the GenBank $^{\mathrm{TM}}$ database under accession numbers: JX290562 (18S); JX290563 (cox1); JX290564 (ITS2).

\section{Results}

\section{Pathological findings}

In case 1, lungs were congested and swollen with multifocal areas of haemorrhages, diffused hepatisation and lobular bronchopneumonia in lobes of the right lung (Figure 1A). The cut surface was oedematous with
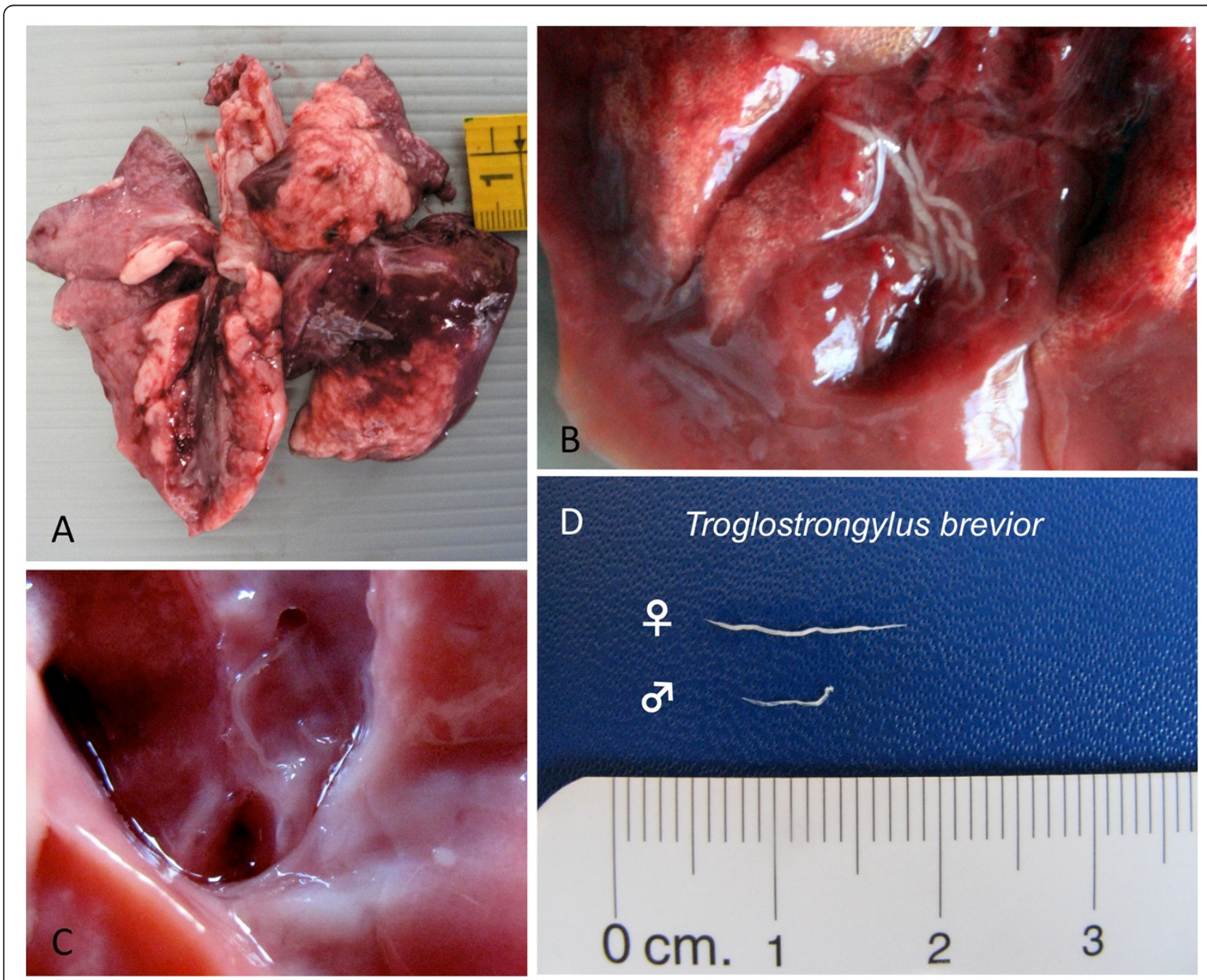

Figure 1 Gross anatomy and parasites collected at the necropsy of case 1. Lungs were congested and swollen, lobular bronchopneumonia was noticed in lobes of the right lung (A). Several parasites were present in respiratory tracts (B-C). A total of twelve slender worms (up to 13 mm length), identified as Troglostrongylus brevior (D), were collected from bronchi and bronchioles. 
catarrhal exudate draining from small airways and parasites were present in respiratory tracts (Figures 1B-1C). Organs of abdominal cavity appeared normal.

In case 2, lungs were diffusely congested and swollen with a large area of consolidation in the right diaphragmatic lobe (Figure 2A). Nematodes mixed with catarrhal exudate were revealed when the trachea was cut (Figure 2B). Other organs and apparatus were normal at gross examination. In both cases, the respiratory failure was identified as the cause of death.

Slender and whitish nematodes (12 from case 1 and 22 from case 2) were collected from bronchi, bronchioles (Figure 1D) and from trachea and large bronchi (Figure 2C) in case 1 and 2, respectively.

\section{Parasite identification}

Parasites collected from case 1 were thin and cylindroid presenting a cuticle that was inflated and thrown into folds. The oesophagus was short and club-shaped, the stoma small and weakly developed. The excretory gland was large and extending almost to the posterior extremity of the body opening, in both sexes, at the first third of the oesophagus (Figure 3A). Nine females and three males were identified. Briefly, females were $6-13 \mathrm{~mm}$ in length and $0.34-0.43 \mathrm{~mm}$ in width with a conical and short tail (125-168 $\mu \mathrm{m})$ and inflated cuticle (Figure 3C; Table 2). The gravid uterus contained larvated eggs. Males were $5-6 \mathrm{~mm}$ in length and $0.43 \mathrm{~mm}$ in width and the oesophagus was 281-301 $\mu$ m length (Table 2). The caudal edge of males showed a well-developed,
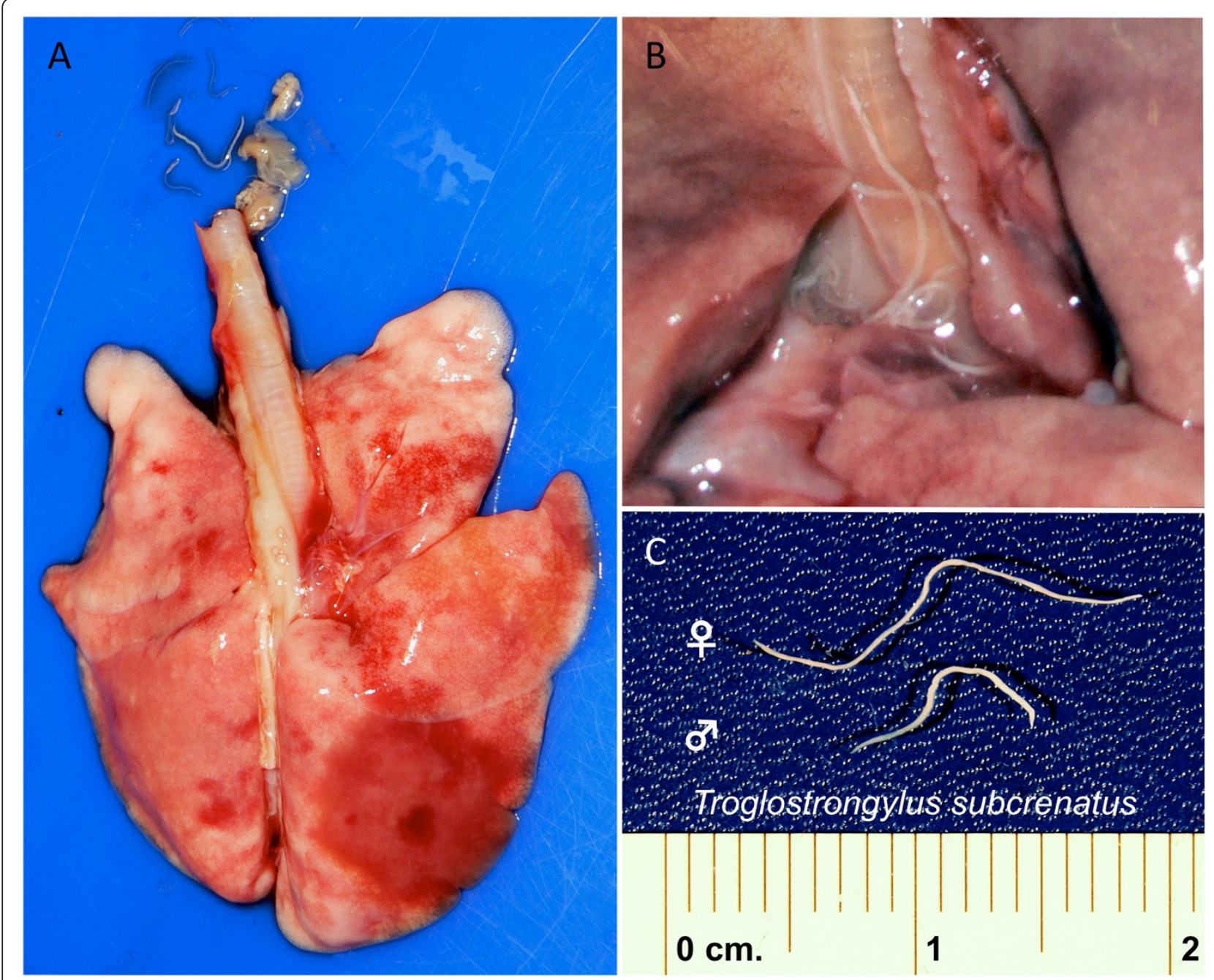

Figure 2 Gross anatomy and parasites collected at the necropsy of case 2. Lungs were diffusely congested and swollen with a large area of consolidation in the right diaphragmatic lobe (A). Parasites mixed with catarrhal exudate were revealed when cutting the trachea (B), A total of twenty-two whitish nematodes (up to $24 \mathrm{~mm}$ length), identified as Troglostrongylus subcrenatus (C) were collected from the trachea and large bronchi. 


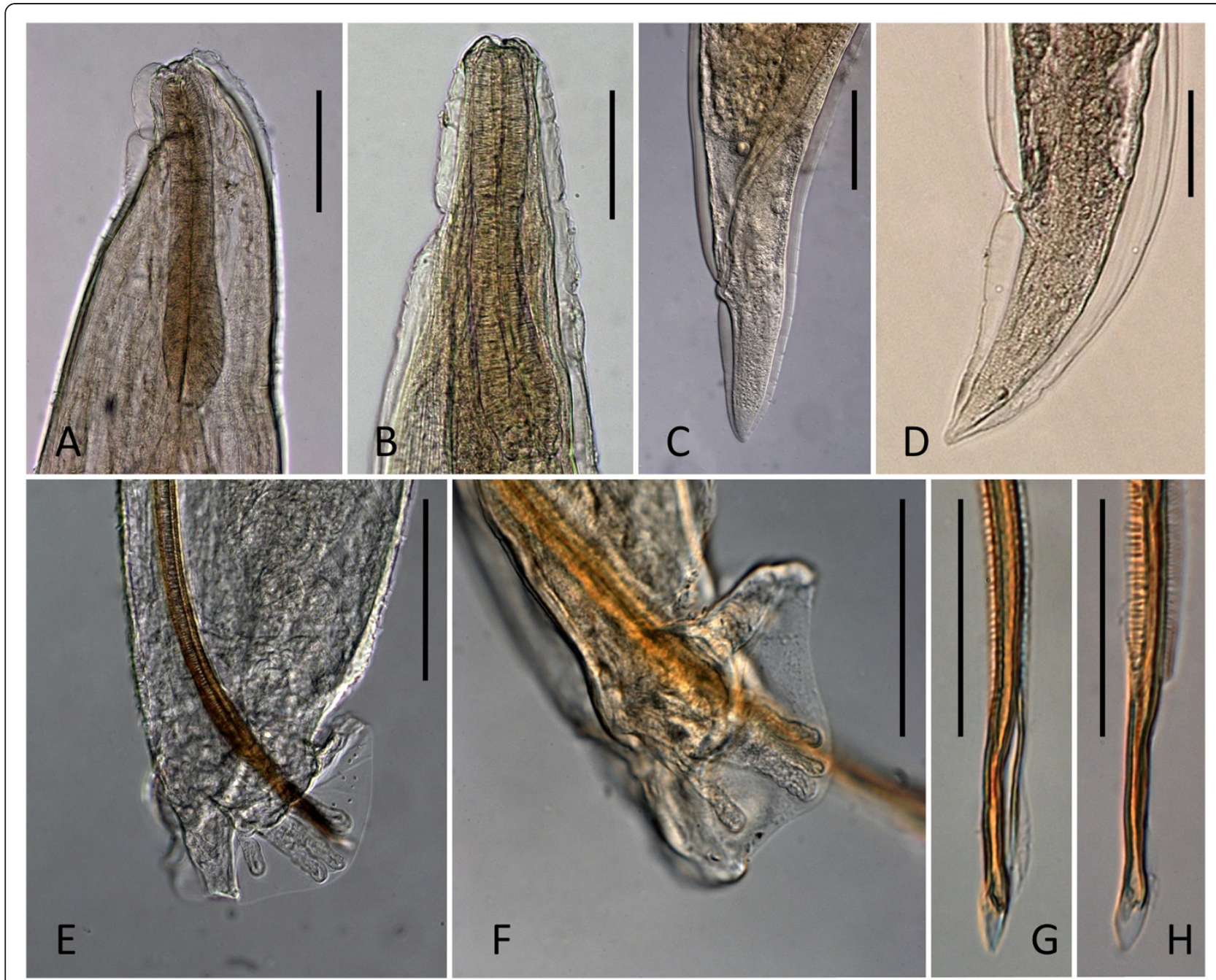

Figure 3 Light microscope images depicting morphometrical differences of cephalic region, caudal region, male bursa and spicules between Troglostrongylus brevior (A, C, E and G) and Troglostrongylus subcrenatus (B, D, F and H). Scale bars = $100 \mu \mathrm{m}(\mathrm{A}-\mathrm{F}), 50 \mu \mathrm{m}(\mathrm{G}-\mathrm{H})$.

Table 2 Anatomical localization and morphometrical features of adult stages of Aelurostrongylus abstrusus, Troglostrongylus brevior and Troglostrongylus subcrenatus

\begin{tabular}{|c|c|c|c|c|c|c|c|}
\hline Species & Localization & Sex & Length (mm) & Width & Oesophagus & Tail (anus-caudal end) & Spicule length \\
\hline \multirow[t]{2}{*}{$\begin{array}{l}\text { Aelurostrongylus abstrusus } \\
\text { (Gerichter, 1949) }\end{array}$} & $\begin{array}{l}\text { Pulmonary } \\
\text { parenchyma }\end{array}$ & Male & $5-6$ & $54-64$ & $240-270$ & - & $130-220$ \\
\hline & & Female & $10-10.4$ & 80 & 300 & $27-29$ & - \\
\hline \multicolumn{8}{|l|}{ Troglostrongylus brevior } \\
\hline \multirow[t]{2}{*}{ (present study) } & $\begin{array}{l}\text { Bronchi and } \\
\text { bronchioles }\end{array}$ & Male $(n=3)$ & $5-6$ & $294-365$ & $281-301$ & - & $600-631$ \\
\hline & & Female $(n=6)$ & $6-13$ & $335-430$ & $272-298$ & $125-168$ & - \\
\hline \multicolumn{8}{|l|}{ Troglostrongylus subcrenatus } \\
\hline \multirow[t]{2}{*}{ (present study) } & Trachea and bronchi & Male $(n=7)$ & $9-10$ & $285-305$ & $255-302$ & - & $613-686$ \\
\hline & & Female $(n=15)$ & $20-24$ & $486-542$ & $283-312$ & $178-189$ & - \\
\hline
\end{tabular}




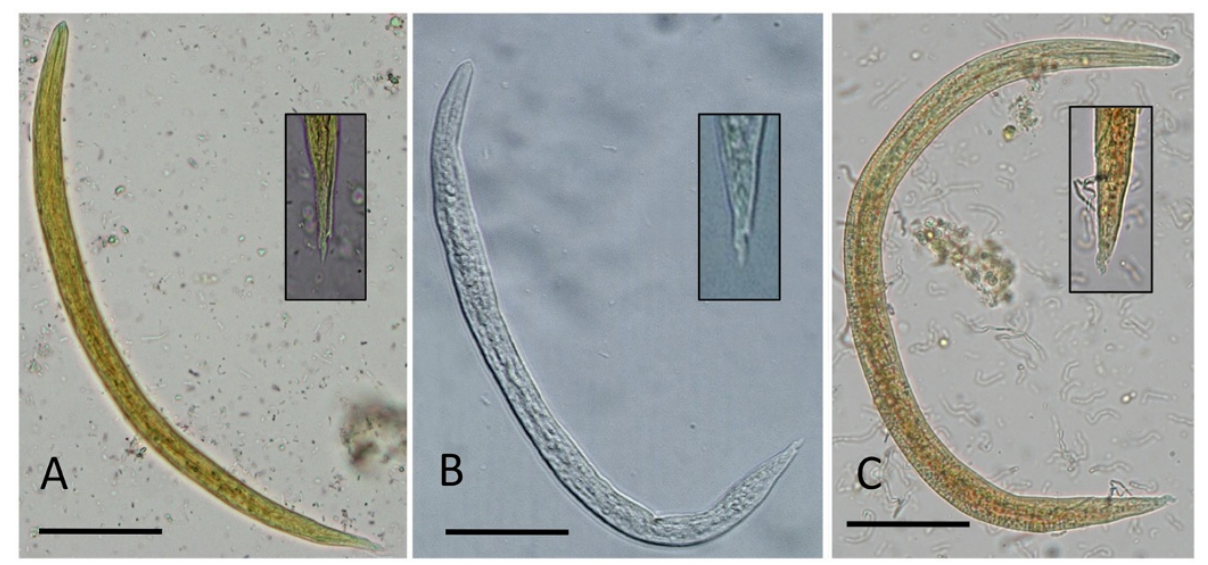

Figure 4 Light microscope images of first stage larvae (L1) of Troglostrongylus brevior (A), Troglostrongylus subcrenatus (B) and Aelurostrongylus abstrusus (C) Magnification of caudal region is provided for each species. Scale bar $=50 \mu \mathrm{m}$.

undivided bursa composed by a dorsal ray elongated with four apical papillae, externo-dorsal and anterolateral rays were well separated, postero- and mediolateral rays joined except for the distal third, ventral rays were short and fused except at their end (Figure 3E). The spicules $(0.60-0.63 \mathrm{~mm})$ were equal in length, thin and transversely striated for most of their extent with serrated edges (Figure 3G; Table 2). First stage larvae (L1) $(339.3 \mu \mathrm{m}$ in length and 18.6 $\mu \mathrm{m}$ in width) had a rhabditoid oesophagus, numerous intestinal cells filled with granules and pointed tail with pronounced dorsal cuticular spine and a shallower ventral one (Figure 4A; Table 3). Morphology and measurements of adult and larval nematodes collected from case 1 were consistent with those of $T$. brevior [17].

Parasites collected from case 2 were stout and filiform nematodes of medium size with a cuticle conspicuously inflated at the anterior end. The oesophagus was clubshaped. The excretory pore opening coincided with the ventral cuticular groove at about the middle of the oesophagus length (Figure 3B). A total of 15 females and seven males were identified. Females $(20-24 \mathrm{~mm}$ in length and 486-542 $\mu \mathrm{m}$ in width) presented a conical and bluntly pointed tail (Figure 3D; Table 2) with the vulva opening posterior to the middle of body and the

Table 3 Mean measurements (microns) of first stage larvae (L1) of Aelurostrongylus abstrusus, Troglostrongylus brevior and Troglostrongylus subcrenatus

\begin{tabular}{lcc}
\hline Species (number of specimens) & \multicolumn{2}{c}{ First stage larvae $($ L1) } \\
\cline { 2 - 3 } & Mean length & Mean width \\
\hline Aelurostrongylus abstrusus $(n=40)$ & $399.1( \pm 11.3)$ & $18.5( \pm 1.2)$ \\
Troglostrongylus brevior $(n=40)$ & $339.3( \pm 14.1)$ & $18.6( \pm 1)$ \\
Troglostrongylus subcrenatus $(n=10)$ & $280.7( \pm 17.9)$ & $15.5( \pm 1.7)$ \\
\hline
\end{tabular}

anus at $178-189 \mu \mathrm{m}$ from the caudal end (Figure 3D). The uteri were filled with larvated eggs. Males (9-10 $\mathrm{mm}$ in length and 285-305 $\mu \mathrm{m}$ in width) presented an undivided bursa composed of a single dorsal stout ray, bearing papillae at the tip and externo-dorsal rays originating independently. Postero- and medio-lateral rays were fused over half or more of the length, antero-lateral rays were single and ventral rays fused for almost their extension (Figure 3F). The spicules (613-686 $\mu \mathrm{m}$ in length) were equal in size and shape, slender and finely striated except for their distal edges. Each spicule was split into two spikes (Figure $3 \mathrm{H}$ ). First stage larvae (280.7 $\mu \mathrm{m}$ in length and $15.5 \mu \mathrm{m}$ in width) had a rhabditoid oesophagus and pointed tail bearing typical dorsal and ventral cuticular spines (Figure 4B; Table 3). Morphology and measurements of adult and larval nematodes collected from case 2 were all consistent with those of T. subcrenatus $[15,31]$.

Morphological and morphometrical features of adult parasites collected from cases 1 and 2 are reported in Table 2 and compared to those of $A$. abstrusus. In spite of the differences in anatomical localization and body size of adult parasites, first stage larvae of $A$. abstrusus, T. brevior and T. subcrenatus are rather similar, except for their slightly differing body lengths and the knob-like terminal end of $A$. abstrusus (see Figure 4 and Table 3).

Adult parasites of $A$. abstrusus were found in respiratory bronchioles and lung parenchyma and gross lesions were characterized by the presence of small greyish subpleural nodules (Figure 5A) containing a mass of larvae, eggs and adult parasites (Figure 5B). Alveoli containing parasites appeared dilated with disrupted septa and encircled by eosinophilic, neutrophilis and mononuclear infiltrate (Figure 5C).

PCR amplification of each target region characterized for nematodes from case 1 resulted in amplicons ranging 

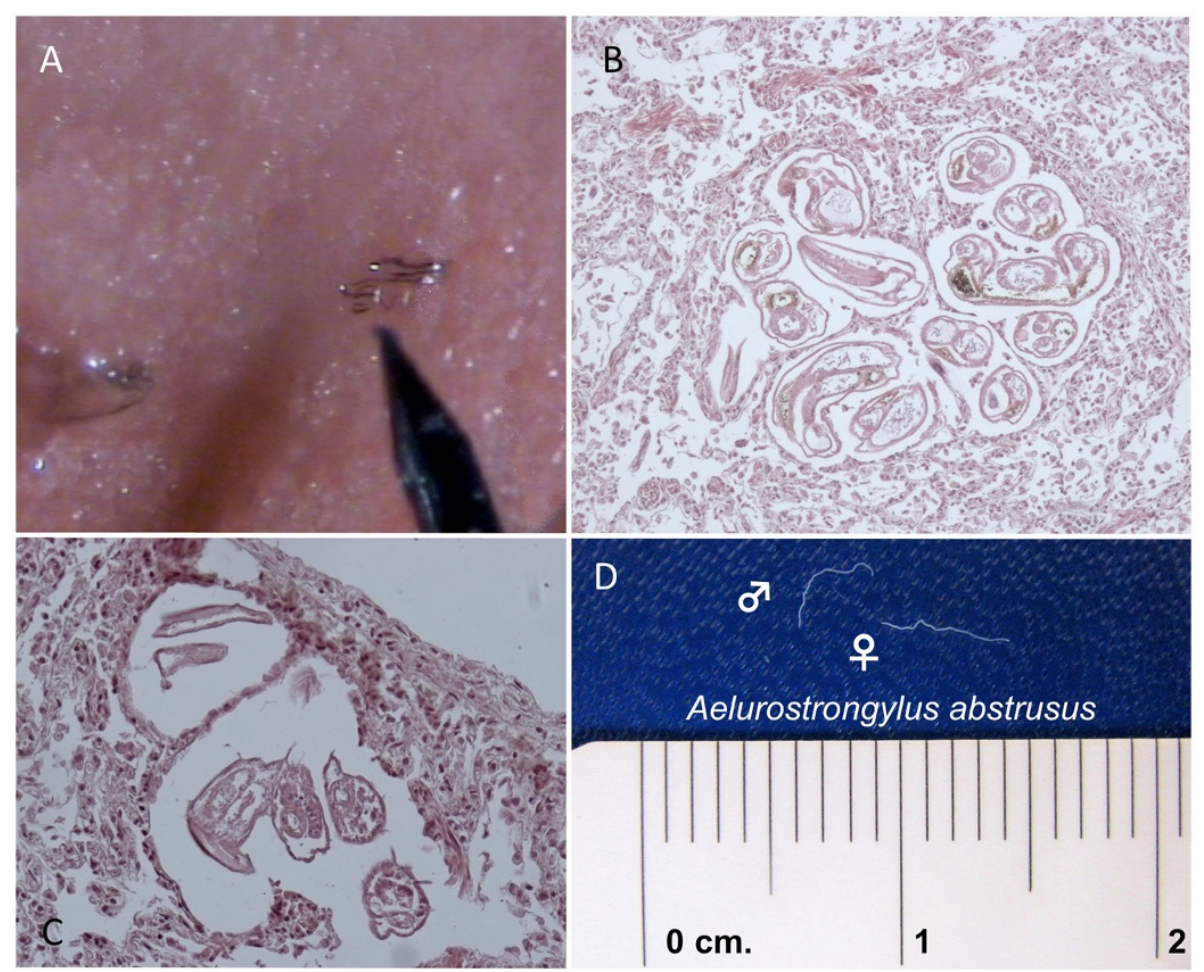

Figure 5 Sub-pleural nodules caused by Aelurostrongylus abstrusus in the lungs of a cat (A) Histological sections (HE) showing localization of adult worms of $A$. abstrusus in the lung parenchyma (B) and in sub-pleural nodules (C) Adult worms (male and female) of $A$. abstrusus (D).

from $\sim 400 \mathrm{bp}(\mathrm{pcox} 1)$ to $\sim 1700 \mathrm{bp}(18 \mathrm{~S})$ and $\sim 630 \mathrm{bp}$ (ITS2). The BLAST analysis of pcox 1 gene sequences showed the closest homology (91\%) with that of Necator americanus (GenBank accession number: AF303151) whereas ITS2 revealed a high homology (99\%, fragment of $89 \mathrm{bp}$ ) when compared with Angiostrongylus cantonensis and Angiostrongylus vasorum (Strongylida: Angiostrongylidae) (GenBank accession numbers: HQ540551 and GU045376, respectively). The $18 \mathrm{~S}$ sequence here produced was identical (homology of 100\%) to Troglostrongylus sp. (GenBank accession number: GU946677).

The phylogenetic analyses of the sequence here produced for $18 \mathrm{~S}$ and ITS2 genes showed a close evolutionary relationship among worms of case 1 with those of Troglostrongylus spp., Otostrongylus spp. and Crenosoma spp. (Strongylida: Crenosomatidae) with relatively strong nodal support, to the exclusion of other metastrongyloids (Figures 6A-B). In particular, the $18 \mathrm{~S}$ tree revealed that the nematode was close to a Troglostrongylus sp. from Spain (Figure 6A).

\section{Discussion}

This paper is the first of all reports on clinical signs and gross lesions associated with $T$. brevior and $T$. subcrenatus infestation in two domestic kittens. The delineation between these two species of metastrongyloids and the most known $A$. abstrusus is pivotal for the aetiological diagnosis of helminthic broncho-pulmonary disease of cats. These two troglostrongylids have been neglected for a long time or underestimated and deserve further investigations to assess their actual geographical distribution and clinical significance, especially in young cats. Indeed, Troglostrongylus spp. have been reported as causative agents of respiratory conditions in many species of wild felids (e.g., Lynx rufus, Panthera pardus, Panthera tigris) [17-21], but their occurrence in domestic cats was considered negligible [22]. Recently, a Troglostrongylus sp. detected in domestic cats exhibiting respiratory signs renewed the scientific interest on this genus [16]. The $18 \mathrm{~S}$ sequences herein produced for $T$. brevior and those derived from the parasitic specimens recently identified [16] provided an a posteriori aetiological identification for the causative agents of the cases above from Spain. This evidence might suggest that Troglostrongylus spp. are more diffuse than currently estimated and that the limited number of records of $T$. brevior and $T$. subcrenatus infesting domestic cats could be due to the close morphological features shared among their L1s (i.e., the parasitic stage mostly used for the diagnosis) with those of $A$. abstrusus. On the other hand, it cannot be 


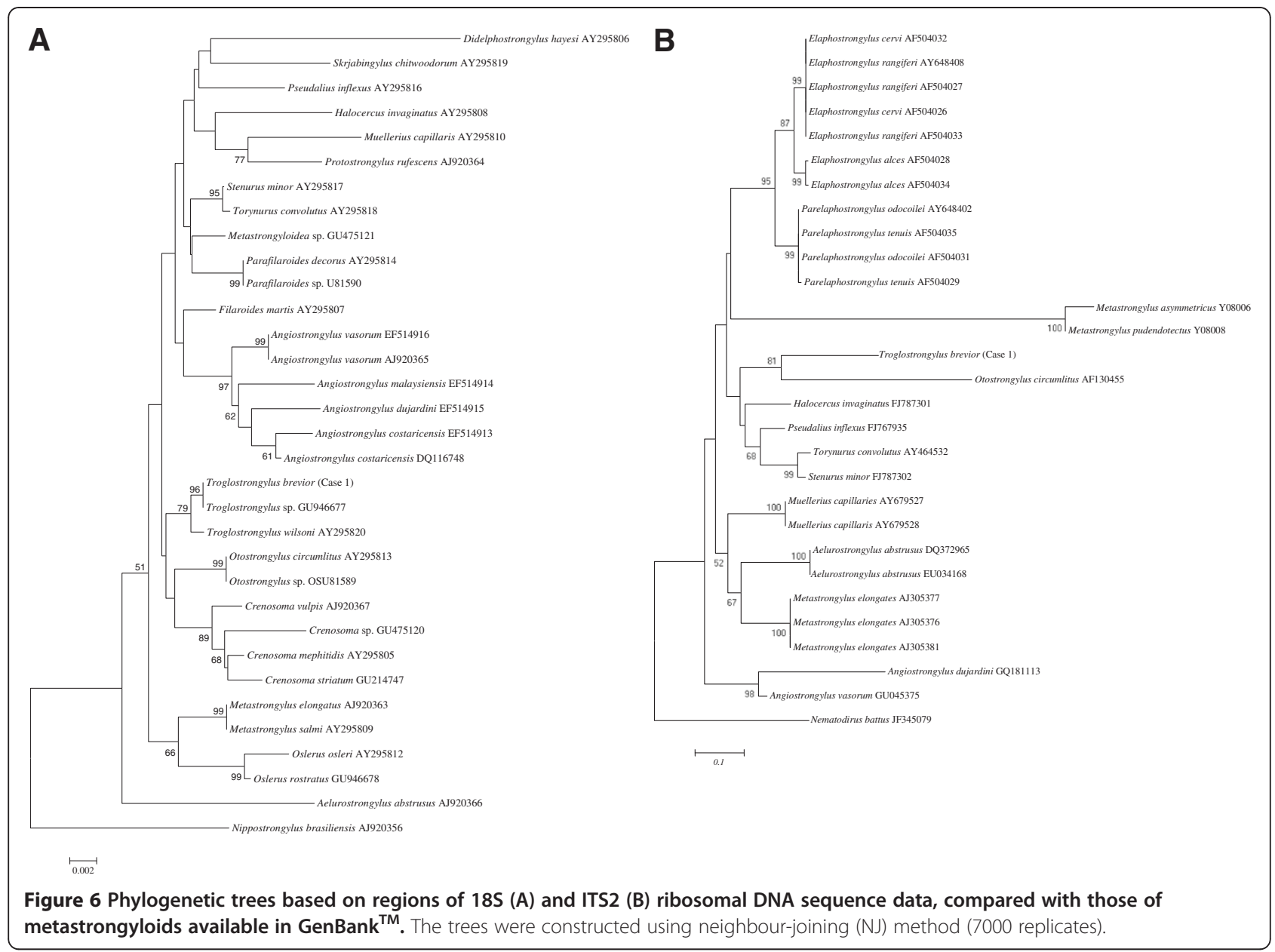

ruled out that troglostrongylosis in domestic cats is limited to areas where cats are more frequently exposed to intermediate and/or paratenic hosts. Furthermore, molluscs of genera (i.e., Helicella spp. Limax spp. and Theba spp.) are common in the locality where both cats reported in this paper came from [32].

Accordingly, almost all data available on lungworms affecting cats are based on copromicroscopical findings [6-12], which might lead to a misdiagnosis unless a thorough morphological and morphometric analysis is undertaken. Even if not easily achievable, an accurate evaluation of morphometrical features (i.e., total length and tail morphology) of L1s may lead to a discrimination among T. brevior, T. subcrenatus and A. abstrusus, being larvae of Troglostrongylus spp. shorter in length and devoid of the typical knob-like terminal end (see Figure 4 and Table 3).

Molecular and phylogenetic analyses presented here provide, for the first time, data on mitochondrial and ribosomal gene sequences of $T$. brevior, giving a dataset for its identification. Based on the analysis of the $18 \mathrm{~S}$ gene, the aetiological cause of infestation in cats from
Ibiza was T. brevior [16]. The phylogenetic analysis of $18 \mathrm{~S}$ further confirms the molecular analysis, clustering T. brevior within other Troglostrongylus spp. infecting domestic carnivores. Nonetheless, further studies should be undertaken to differentiate $T$. brevior and $T$. subcrenatus molecularly in order to better understand their pathogenicity, biology and bionomics (including the role of different species of molluscs as intermediate hosts) and infer their potential spread throughout Europe. A molecular characterization of these two species might contribute to assessing a specific and sensitive molecular tool for the detection of both species in faeces and pharyngeal swabs, as recently validated for A. abstrusus [33].

The greater body size of T. brevior and T. subcrenatus in comparison with $A$. abstrusus and their anatomical localisation in the upper respiratory airways (i.e., bronchioles and large bronchi) also reflects differences in the presentations and severity of clinical signs they cause in cats. Indeed, both clinical cases here described exhibited severe respiratory distress and had a lethal outcome due to respiratory failure. Accordingly, most of the lung damage observed at 
the gross examination was associated with the presence and action of nematode specimens. This clinical picture differs from that caused by $A$. abstrusus, which generally induces minor signs and is reported as an often self-limiting parasite $[1,5,34]$. Nonetheless, the clinical presentation caused by Troglostrongylus spp. and $A$. abstrusus may overlap in simultaneously infested animals, thus making any definitive aetiological diagnosis based on respiratory signs difficult.

Troglostrongylus brevior and T. subcrenatus share similar biology with $A$. abstrusus, all involving mollusc intermediate hosts in their life cycle $[4,17,22]$ and thus, most likely, occupying the same ecological niches and occurring simultaneously in a given host population, as confirmed by co-infestation in the same cat population from Ibiza [16]. Due to their capacity of developing to the infective stage under different climatic conditions in many species of intermediate hosts, troglostrongylids may have a potential broader distribution than currently believed. Indeed, larvae of $T$. brevior show the highest resistance in the environment, developing to the infective stage at low temperatures (i.e., $4-8^{\circ} \mathrm{C}$ in 40 days) but not $A$. abstrusus, even when kept up to 7 months at the same conditions [17]. Under optimal conditions (i.e., 22-27 ${ }^{\circ} \mathrm{C}$ ) T. brevior displays the shortest development time (i.e., 8 days) known for any metastrongyloid species [17], suggesting that this species may potentially express a higher parasitic pressure for feline populations than $A$. abstrusus.

\section{Conclusion}

Data presented here indicate that T. brevior and T. subcrenatus may occur in domestic cats causing overt respiratory disease. Moreover, these two species should be included, along with $A$. abstrusus, in the differential diagnosis of bronchopulmonary affections in cats. Although the delineation of L1s among metastrongyloids is achievable using morphometrical criteria, molecular biology tools should be considered and implemented toward enhancing current knowledge on the biology, epidemiology and control of Troglostrongylus spp. infestations in domestic cats.

\section{Additional file}

Additional file 1: Dyspnoea caused by Troglostrongylus brevior Movie shows severe inspiratory and expiratory dyspnoea associated with Troglostrongylus brevior infestation.

Additional file 2: Respiratory symptoms caused by Troglostrongylus brevior Movie shows respiratory symptoms (coughing and dyspnoea) observed in a kitten infested by Troglostrongylus brevior.

\section{Competing interest}

The authors declare that they have no competing interests.

\section{Authors' contributions}

EB conceived the study, documented clinical cases, described parasites and drafted the manuscript. GG and SG collected parasites, performed the morphological identification and revised the drafts of the manuscript. GA and MSL carried out the molecular genetic studies, sequence alignment and phylogenetic analyses, and drafted the manuscript. DT and FDT revised the drafts of manuscript. DO participated in molecular genetic and phylogenetic studies and revised and implemented the drafts of manuscript. All authors read and approved the final version of manuscript.

\section{Author details}

${ }^{1}$ Dipartimento di Sanità Pubblica Veterinaria, Facoltà di Medicina Veterinaria, Università degli Studi di Messina, Messina, Italy. ${ }^{2}$ Dipartimento di Sanità Pubblica e Zootecnia, Facoltà di Medicina Veterinaria, Università degli Studi di Bari, Valenzano, BA, Italy. ${ }^{3}$ Departamento de Imunologia, Centro de Pesquisas Aggeu Magalhães, Fundação Oswaldo Cruz, Recife, PE, Brazil. ${ }^{4}$ Dipartimento di Scienze Biomediche Comparate, Facoltà di Medicina Veterinaria, Università degli Studi di Teramo, Teramo, Italy.

Received: 25 June 2012 Accepted: 12 August 2012

Published: 23 August 2012

\section{References}

1. Traversa D, Guglielmini C: Feline aelurostrongylosis and canine angiostrongylosis: a challenging diagnosis for two emerging verminous pneumonia infections. Vet Parasitol 2008, 157:163-174.

2. Traversa D, Di Cesare A, Conboy G: Canine and feline cardiopulmonary parasitic nematodes in Europe: emerging and underestimated. Parasit Vectors 2010, 3:62

3. Di Cesare A, Castagna G, Meloni S, Milillo P, Latrofa S, Otranto D, Traversa D: Canine and feline infections by cardiopulmonary nematodes in central and southern Italy. Parasitol Res 2011, 109:87-96.

4. Anderson RC: Nematode Parasites of Vertebrates. In Their Development and Transmission. 2nd edition. New York: CABI Publishing; 2000.

5. Bowman DD, Hendrix CM, Lindsay DS, Barr SC: Feline Clinical Parasitology. Ames: lowa State University Press; 2002.

6. Miró G, Montoya A, Jiménez S, Frisuelos C, Mateo M, Fuentes I: Prevalence of antibodies to Toxoplasma gondii and intestinal parasites in stray, farm and household cats in Spain. Vet Parasitol 2004, 126:249-255.

7. Payo-Puente P, Botelho-Dinis M, Carvaja Urueña AM, Payo-Puente M, Gonzalo-Orden JM, Rojo-Vazquez FA: Prevalence study of the lungworm Aelurostrongylus abstrusus in stray cats of Portugal. J Feline Med Surg 2008, 10:242-246.

8. Traversa D, Lia RP, lorio R, Boari A, Paradies P, Capelli G, Avolio S, Otranto D: Diagnosis and risk factors of Aelurostrongylus abstrusus (Nematoda, Strongylida) infection in cats from Italy. Vet Parasitol 2008, 153:182-186.

9. Taubert A, Pantchev N, Vrhovec MG, Bauer C, Hermosilla C: Lungworm infections (Angiostrongylus vasorum, Crenosoma vulpis, Aelurostrongylus abstrusus) in dogs and cats in Germany and Denmark in 2003-2007. Vet Parasitol 2009, 159:175-180.

10. Mircean V, Titilincu A, Vasile C: Prevalence of endoparasites in household cat (Felis catus) populations from Transylvania (Romania) and association with risk factors. Vet Parasitol 2010, 171:163-166.

11. Barutzki D, Schaper R: Results of parasitological examinations of faecal samples from cats and dogs in Germany between 2003 and 2010. Parasitol Res 2011, 109:45-60.

12. Knaus M, Kusi I, Rapti D, Xhaxhiu D, Winter R, Visser M, Rehbein S: Endoparasites of cats from the Tirana area and the first report on Aelurostrongylus abstrusus (Railliet, 1898) in Albania. Wien Klin Wochenschr 2011, 123:31-35.

13. Juste RA, Garcia AL, Mencia L: Mixed infestation of a domestic cat by Aelurostrongylus abstrusus and Oslerus rostratus. Angew Parasitol 1992, 33:56-60.

14. Millán J, Casanova JC: High prevalence of helminth parasites in feral cats in Majorca Island (Spain). Parasitol Res 2009, 106:183-188.

15. Fitzsimmons WM: Bronchostrongylus subcrenatus (Raillet \& Henry, 1913) a new parasite recorded from the domestic cat. Vet Rec 1961, 73:101-102.

16. Jefferies R, Vrhovec MG, Wallner N, Catalan DR: Aelurostrongylus abstrusus and Troglostrongylus sp. (Nematoda: Metastrongyloidea) infections in cats inhabiting Ibiza, Spain. Vet Parasitol 2010, 173:344-348. 
17. Gerichter CB: Studies on nematodes parasitic in the lungs of felidae in Palestine. Parasitology 1949, 39:251-262.

18. Sarmiento L, Stough BD: Troglostrongylus wilsoni (Stough, 1953) n.comb. (Nematoda: Metastrongylidae) from the lungs of the bobcat, Lynx rufus rufus. J Parasitol 1956, 42:45-48.

19. Watson TG, Nettles VF, Davidson WR: Endoparasites and selected infectious agents in bobcats (Felis rufus) from West Virginia and Georgia. J Wildl Dis 1981, 17:547-554.

20. Smith JD, Addison EM, Joachim DG, Smith LM, Quinn NWS: Helminth parasites of Canada lynx (Felis canadensis) from northern Ontario. Can J Zool 1986, 64:358-364.

21. Reichard MV, Caudell DL, Kocan AA: Survey on helminth lung parasites of bobcats (Lynx rufus) from Alabama, Kansas, New Mexico, Oklahoma, and Virginia. U.S.A. Comp Parasitol 2004, 71:88-90.

22. Soulsby ELL: Helminths, Arthropods and Protozoa of Domesticated Animals. 7th edition. London: Baillère Tindall; 1982.

23. Skryabin Kl, Shikhobalova NP, Schulz RS, Popova TI, Boev SN, Delyamure SL: Key to Parasitic Nematodes, Volume 3. Koln: E.J. BRILL; 1992.

24. Sharrocks AD: The design of primers for PCR. In PCR Technology. Edited by Griffin HG, Griffin AM. London: Current Innovations. CRC Press; 1994:5-11.

25. Patterson-Kane JC, Gibbons LM, Jefferies R, Morgan ER, Wenzlow N, Redrobe SP: Pneumonia from Angiostrongylus vasorum infection in a red panda (Ailurus fulgens fulgens). J Vet Diagn Invest 2009, 21:270-273.

26. Otranto D, Tarsitano E, Traversa D, Giangaspero A, De Luca F, Puccini V: Differentiation among three species of bovine Thelazia (Nematoda: Thelaziidae) by polymerase chain reaction-restriction fragment length polymorphism of the first internal transcribed spacer ITS-1 (rDNA). Int J Parasitol 2001, 31:1693-1698.

27. Tamura K, Peterson D, Peterson N, Stecher G, Nei M, Kumar S: MEGA5: molecular evolutionary genetics analysis using maximum likelihood, evolutionary distance, and maximum parsimony methods. Mol Biol Evol 2011, 28:2731-2739.

28. Altschul SF, Madden TL, Schäffer AA, Zhang J, Zhang Z, Miller W, Lipman DJ: Gapped BLAST and PSI-BLAST: a new generation of protein database search programs. Nucleic Acids Res 1997, 25:3389-3402.

29. Saitou N, Nei M: The neighbor-joining method: a new method for reconstructing phylogenetic trees. Mol Biol Evol 1987, 4:406-425.

30. Felsenstein J: Confidence limits on phylogenies: an approach using the bootstrap. Evolution 1985, 39:783-791.

31. Fitzsimmons WM: On a redescription of the male of Troglostrongylus subcrenatus (Raillet \& Henry, 1913) n. comb., from the domestic cat and the synonymy of Bronchostrongylus Cameron, 1931 with Troglostrongylus Vevers, 1923. J Helminthol 1964, 38:11-20.

32. Cossignani T, Cossignani V: Atlante delle conchiglie terrestri e dulciacquicole italiane. Ancona (Italia): L'informatore Piceno; 1995.

33. Traversa D, Di Cesare A, Milillo P, lorio R, Otranto D: Aelurostrongylus abstrusus in a feline colony from central Italy: clinical features diagnostic procedures and molecular characterization. Parasitol Res 2008, 103:11911196.

34. Pennisi MG, Niutta PP, Giannetto S: Lung worm disease in cats caused by Aelurostrongylus abstrusus. Tijdschr Diergeneeskd 1995, 120:263-266.

doi:10.1186/1756-3305-5-178

Cite this article as: Brianti et al.: Troglostrongylus brevior and

Troglostrongylus subcrenatus (Strongylida: Crenosomatidae) as agents of broncho-pulmonary infestation in domestic cats. Parasites \& Vectors 2012 5:178.

\section{Submit your next manuscript to BioMed Central and take full advantage of:}

- Convenient online submission

- Thorough peer review

- No space constraints or color figure charges

- Immediate publication on acceptance

- Inclusion in PubMed, CAS, Scopus and Google Scholar

- Research which is freely available for redistribution 